This item was submitted to Loughborough's Research Repository by the author.

Items in Figshare are protected by copyright, with all rights reserved, unless otherwise indicated.

\title{
Conductive microfluidic interconnects to enable scalable 3D manufacturing of wearable electronics
}

PLEASE CITE THE PUBLISHED VERSION

http://dx.doi.org/10.1109/ECTC.2016.24

PUBLISHER

(C) IEEE

VERSION

AM (Accepted Manuscript)

LICENCE

CC BY-NC-ND 4.0

\section{REPOSITORY RECORD}

Flowers, Jonathan, Changqing Liu, Sean R. Mitchell, Andy R. Harland, and Dale W. Esliger. 2019. "Conductive Microfluidic Interconnects to Enable Scalable 3D Manufacturing of Wearable Electronics". figshare. https://hdl.handle.net/2134/21543. 


\title{
Conductive Microfluidic Interconnects to Enable Scalable 3D Manufacturing of Wearable Electronics
}

\author{
Jonathan Flowers ${ }^{1,3}$, Changqing Liu ${ }^{1}$, Sean Mitchell ${ }^{1}$, Andy Harland ${ }^{1}$, Dale Esliger ${ }^{2,3}$ \\ ${ }^{1}$ Wolfson School of Mechanical, Manufacturing and Electrical Engineering \\ ${ }^{2}$ School of Sport, Exercise and Health Sciences \\ ${ }^{3}$ National Centre for Sports and Exercise Medicine \\ Loughborough University, Loughborough, Leicestershire, LE11 3TU, UK \\ e-mail: j.b.flowers@lboro.ac.uk, c.liu@lboro.ac.uk
}

\begin{abstract}
This paper investigates the geometry and surface finish of channels machined into polydimethylsiloxane using a continuous wave $\mathrm{CO} 2$ laser. In order to investigate the various mechanisms, that could affect the channel geometry, both the laser power and trace speed were varied in conjunction with the use of a fixed focal size to allow comparison between configurations. It was discovered that as the power level increases, repeatability decreases while dimensional variability of the channel along its length and multiple iterations increases. It was found that the power output of the laser has a greater effect on the dimensions of the channels than the total energy input into the material. Varying configurations were used when creating these channels resulting in a strong correlation between both power and speed with regard to depth. However, at higher energy levels this relationship appears to break down and the depth of the cut reduces when compared to similar laser configurations at a lower power level.
\end{abstract}

Keywords - laser machining; microfluidics manufacture; galinstan;

\section{INTRODUCTION}

Wearable electronics are a set of technologies and devices that can be worn to track information related to health and fitness markers and sometimes even include location and activity data. These wearable devices must be thin, flexible, stretchable and conformal to the human body [1]. Low cost and scalable conformal electronics are currently seen as the gold standard for on-body sensor networks; however, their manufacture has remained elusive, as it demands disruptive changes to technologies when compared to conventional electronics, which are usually rigid. In order to achieve this, various challenges and bottlenecks exist with regard to both the design and manufacture of electronics [2]. Conventional interconnect materials such as copper, gold and tin alloys can become the victims of their own mechanical properties, as for a device to be flexible and stretchable, these materials need to be capable of repeated elastic and plastic deformation, which will quickly lead to metal fatigue jeopardizing the reliability of the products [3]. To solve this problem this study proposes the use of unique high conductivity metallic interconnects are proposed, which can be deformed without inducing fatigue through the use of a room temperature liquid metal called Galinstan in this study [4].
The use of Galinstan as a conductor does introduce a new set of hurdles that would need to be overcome in order to bring these technologies to tangible applications. Due to Galinstan being a liquid, it must be fully encapsulated within a confined channel in order to prevent any change in geometry of the conductors. For the channels that have to be fabricated to carry Galinstan liquid, the manufacturing method must be capable of varying channel geometry across the length of the channel. An additional challenge that requires a solution is to include vertical vias that are able to form a three dimensional electronic interconnect structure or circuit design [5]. Conventional methods that are used to create these channels for Lab on Chip applications normally involve the use of complex lithography, molding or embossing techniques [6], which can introduce problems when creating holes directly through the substrate in order to enable vertical interconnects. One of these issues is requiring sacrificial layers in order to create a single component, which when scaled can lead to increased costs [7].

The use of conductive fluids such as Galinstan for interconnects contained within a soft, flexible substrate has been shown to be a promising direction for the manufacture of such devices, which, can fit well with existing Roll2Roll approach for scalable manufacturing of fluidic channels. It is desirable to have the ability to fabricate 3D interconnected channels on a suitable flexible substrate, for which the process is capable of high throughput, and is scalable at reasonable costs for production and mass manufacture of low cost devices. In this work, several potential scalable methods for creating the channels have been investigated for the direct fabrication of microfluidic channels within a Polydimethylsiloxane (PDMS) substrate. The use of lasers as a processing tool allows the creation of a varied channel sizes in addition to drilling and cutting directly through the material.

This paper aims to identify the optimal laser cutting parameters using a continuous wave Carbon Dioxide laser for the cutting and engraving of a PDMS substrate. The use of a $\mathrm{CW} \mathrm{CO}_{2}$ laser allows the low cost, continuous manufacture of PDMS based microfluidic devices with few if any restrictions on channel geometry, while being capable of small-scales and high precision. Various laser parameters such as power levels, trace speed and repetitions were tested to narrow down the optimal combination in order to create a uniform high quality cut and surface finish. This has led to a 
data set that was produced to enable the correct selection of parameters when machining PDMS with a $\mathrm{CW} C \mathrm{CO} 2$ laser. An evaluation of the quality of the obtained channels was subsequently carried out using various metrology tools to provide a clear understanding of the effects of laser processing parameters on the surface finish, depth and geometry of the machined channel in the PDMS substrate. It is envisaged that the use of low cost $\mathrm{CW} \mathrm{CO} 2$ lasers in both the small-scale prototyping and mass manufacture of microfluidic channels on PDMS substrates will be viable for scalable 3D manufacturing of wearable electronics. A tangible wearable device will be designed at a later stage, to demonstrate the processes being developed in this study.

\section{METHODS AND MATERIALS}

\section{A. Polydimethylsiloxane (PDMS) Substrate}

PDMS (Dow Corning Sylgard 184 blended in a 10:1 ratio of resin to hardener) sheets, with a nominal thickness of $4 \mathrm{~mm}$ were produced in $200 \mathrm{~mm}$ by $200 \mathrm{~mm}$ squares and cured at $22^{\circ} \mathrm{C}$ for 48 hours, were selected as the substrate.

\section{B. Laser Set-up}

The laser used for the fabrication of via holes and channels was a $100 \mathrm{~W}$ Synrad $\mathrm{CO}_{2}$ Marking Laser with an FH Flyer Marking head, also manufactured by Synrad. The laser was configured with a focal point of $300 \mu \mathrm{m}$ and has a characteristic wavelength of $10.6 \mu \mathrm{m}$. A CO2 laser was chosen due to its ability to easily cut the polymer substrate, other types such as Nd:YAG and Excimer lasers were tested but either were not able to cut the polymer due to incompatible emission and absorption spectra or were too slow to be used in a viable continuous production process. The laser is a continuous wave unit that uses Pulse Width Modulation to adjust the power level of the laser. The configuration settings exposed to the user include the power output, as a percentage of $100 \mathrm{~W}$ and trace speed, up to a maximum value of $990 \mathrm{~mm} / \mathrm{s}$.

\section{Channel Fabrication}

To quantify the effect of the laser configuration on channel geometry and quality, a range of parameters were

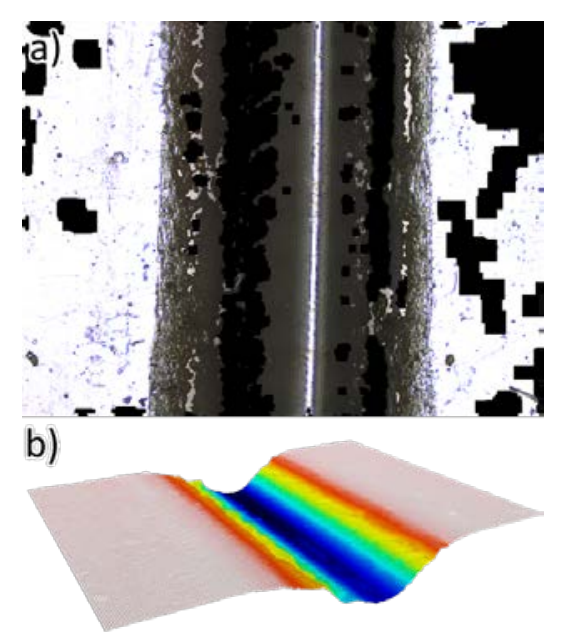

Figure 1. a) Channel Texture bitmap and b) depth map (Sample 1 $80 \mathrm{~W}$ at $100 \mathrm{~mm} / \mathrm{s}$ ) tested. These include three power settings $(60 \mathrm{~W}, 80 \mathrm{~W}$ $100 \mathrm{~W}$ ) in combination with nine speed settings between $250 \mathrm{~mm} / \mathrm{s}$ and $50 \mathrm{~mm} / \mathrm{s}$ in $25 \mathrm{~mm} / \mathrm{s}$ intervals for comparison and evaluation. They are summarized in Table 1. Each combination of parameters was tested three times in order to identify the repeatability of the process. Eighty-one lines, $20 \mathrm{~mm}$ in length and with $10 \mathrm{~mm}$ spacing between each line were marked onto the pre-prepared PDMS substrate. Once all cuts were made, the sample was diced into groups of three lines and washed with isopropyl alcohol, then dried with clean air blasts. Once dried the samples were then sputtered with a $12 \mathrm{~nm}$ AuPd layer to facilitate imaging and surface profiling.

\section{TABLE I. LASER CONFIGURATIONS USED}

\begin{tabular}{|c|c|c|c|}
\hline $\begin{array}{c}\text { Laser Power } \\
\text { Levels }\end{array}$ & $\begin{array}{c}\text { Focal } \\
\text { Diameter }\end{array}$ & $\begin{array}{l}\text { Trace } \\
\text { Speed }\end{array}$ & $\begin{array}{c}\text { Energy Output per } \\
\mathrm{m}^{2}\end{array}$ \\
\hline \multirow{9}{*}{$100 \mathrm{~W}$} & \multirow{27}{*}{$0.3 \mathrm{~mm}$} & $250 \mathrm{~mm} / \mathrm{s}$ & 1333.33 \\
\hline & & $225 \mathrm{~mm} / \mathrm{s}$ & 1481.48 \\
\hline & & $200 \mathrm{~mm} / \mathrm{s}$ & 1666.67 \\
\hline & & $175 \mathrm{~mm} / \mathrm{s}$ & 1904.76 \\
\hline & & $150 \mathrm{~mm} / \mathrm{s}$ & 2222.22 \\
\hline & & $125 \mathrm{~mm} / \mathrm{s}$ & 2666.67 \\
\hline & & $100 \mathrm{~mm} / \mathrm{s}$ & 3333.33 \\
\hline & & $75 \mathrm{~mm} / \mathrm{s}$ & 4444.44 \\
\hline & & $50 \mathrm{~mm} / \mathrm{s}$ & 6666.67 \\
\hline \multirow{9}{*}{$80 \mathrm{~W}$} & & $250 \mathrm{~mm} / \mathrm{s}$ & 1066.67 \\
\hline & & $225 \mathrm{~mm} / \mathrm{s}$ & 1185.19 \\
\hline & & $200 \mathrm{~mm} / \mathrm{s}$ & 1333.33 \\
\hline & & $175 \mathrm{~mm} / \mathrm{s}$ & 1523.81 \\
\hline & & $150 \mathrm{~mm} / \mathrm{s}$ & 1777.78 \\
\hline & & $125 \mathrm{~mm} / \mathrm{s}$ & 2133.33 \\
\hline & & $100 \mathrm{~mm} / \mathrm{s}$ & 2666.67 \\
\hline & & $75 \mathrm{~mm} / \mathrm{s}$ & 3555.56 \\
\hline & & $50 \mathrm{~mm} / \mathrm{s}$ & 5333.33 \\
\hline \multirow{9}{*}{$60 \mathrm{~W}$} & & $250 \mathrm{~mm} / \mathrm{s}$ & 800.00 \\
\hline & & $225 \mathrm{~mm} / \mathrm{s}$ & 888.89 \\
\hline & & $200 \mathrm{~mm} / \mathrm{s}$ & 1000.00 \\
\hline & & $175 \mathrm{~mm} / \mathrm{s}$ & 1142.86 \\
\hline & & $150 \mathrm{~mm} / \mathrm{s}$ & 1333.33 \\
\hline & & $125 \mathrm{~mm} / \mathrm{s}$ & 1600.00 \\
\hline & & $100 \mathrm{~mm} / \mathrm{s}$ & 2000.00 \\
\hline & & $75 \mathrm{~mm} / \mathrm{s}$ & 2666.67 \\
\hline & & $50 \mathrm{~mm} / \mathrm{s}$ & 4000.00 \\
\hline
\end{tabular}




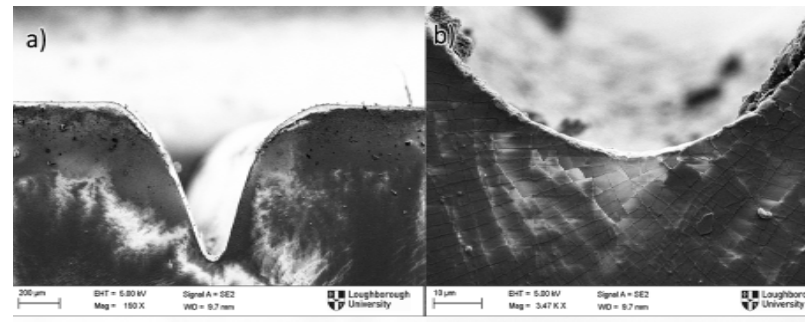

c)

d)

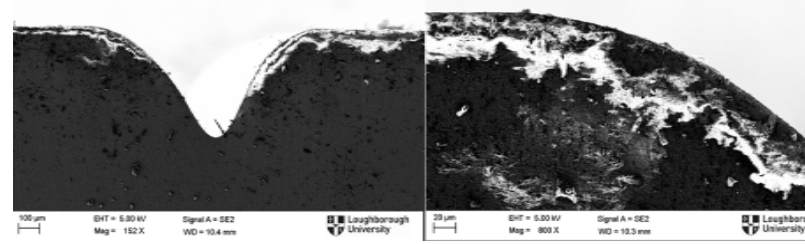

Figure 2. FEGSEM Images of two samples, which demonstrate some of the artifacts that are left around the channel after processing. Images a) and b) are from a $100 \mathrm{~W}$ exposure at $50 \mathrm{~mm} / \mathrm{s}$ and demonstrate what appears to be thermal induced fracture of the material. Images c) and d) are from a $100 \mathrm{~W}$ exposure at $75 \mathrm{~mm} / \mathrm{s}$ and clearly show re-deposition along the edges of the groove.

\section{Characteriasation: Data Acquisition}

Each of the diced segments were imaged using an Alicona InfiniteFocus with a 10x magnification lens, however, the lines cut at $100 \mathrm{~W} 50 \mathrm{~mm} / \mathrm{s}-100 \mathrm{~mm} / \mathrm{s}$ were imaged with $5 \mathrm{x}$ magnification. The system was configured to acquire a lateral resolution of $3 \mu \mathrm{m}$ and a vertical resolution of $750 \mathrm{~nm}$.

The system produced both texture images and threedimensional depth profile maps. Typical examples are shown in Figure 1.

Field Emission Gun Scanning Electron Microscope (FEGSEM) images were taken of a selection of cross section from some samples in order to observe any changes to the material structure and any re-deposition that may be

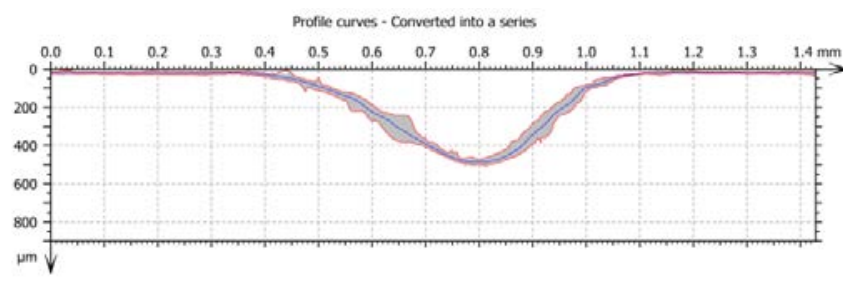

Figure 3. Profile curve stack (grey) showing upper and lower envelopes (red) and mean (blue) for Sample $1-80 \mathrm{~W}$ at $100 \mathrm{~mm} / \mathrm{s}$

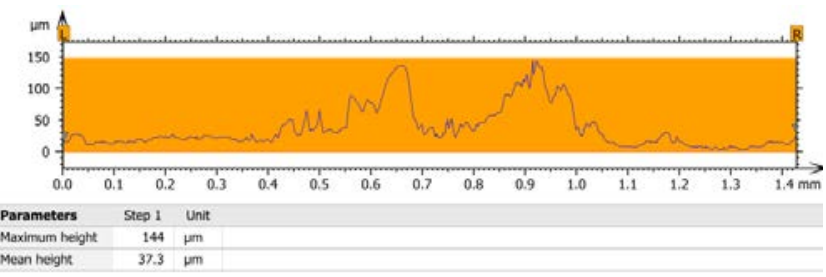

Figure 4. Profile curve range calculated as the difference between upper and lower envelopes as seen in Figure 2. occurring. These cross sections also allowed observation of some of the surface qualities of the channels as well as any kind of thermal fracture that may be occurring. A selection of these images can be seen in Figure 2. These images include a close up of the entire channels as well as some of the artifacts that could be seen occurring around the channel itself like in Figures 2(b) and 2(d).

\section{E. Characteriasation: Data Analysis}

Depth profile maps were imported into Digital Surf MountainsMap Premium 7.2, where various analysis tools can be accessed to carry out and extract various metrics for the channels that were laser machined. Channel depth was measured using two methods: i) by calculating the maximum depth using every profile across the $1.4 \mathrm{~mm}$ imaged sample, ii) by using the "Valley Depth Tool" which intelligently identifies the bottom of the valley and averages only those points. The latter was preferable to the profile tool, as the deepest part of the channel may not always be

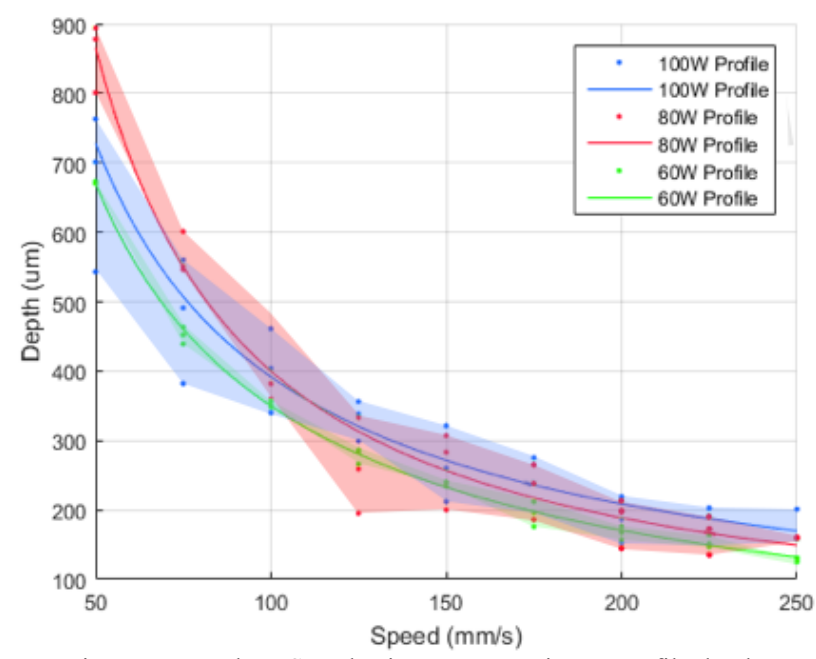

Figure 5. Depth vs Speed using mean maximum profile depth

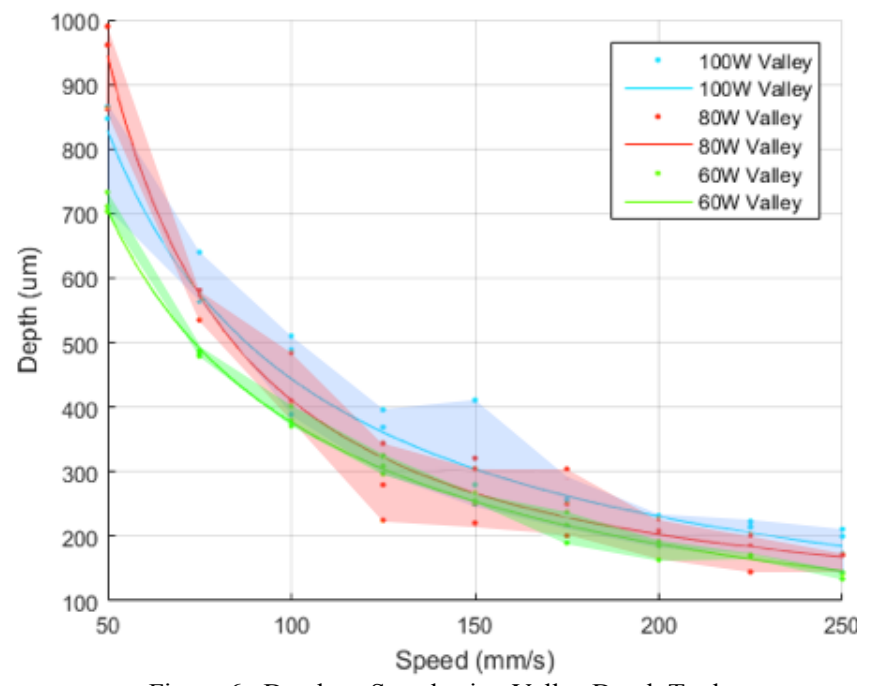

Figure 6. Depth vs Speed using Valley Depth Tool 
vertically aligned. Channel quality was evaluated using the upper and lower envelopes of all the profiles (Figure 3) and a difference calculated at each point as can be seen in Figure 4.

The channel edge shape was identified qualitatively as either having a smooth or blunt transition. An example of smooth transitions can be seen in Figures 1 and 2. A blunt transition is a sharper transition that actually has a ridge; edges of this type were quite uncommon.

\section{RESULTS AND DISCUSSION}

The results can be divided into two categories, channel profile shape and surface finish. Profile shape covers the channel geometry such as channel depth, channel quality, slope angle and edge transition type. Surface finish covers the waviness and surface roughness of the channel.

\section{A. Channel Profile: Depth Analysis}

Data for the channel depth displayed in Figures 5 and 6. It can be seen that when the cut was made using $100 \mathrm{~W}$ power at speeds below $125 \mathrm{~mm} / \mathrm{s}$ the depth did not increase as expected. The expected result was that as the power level increases the channel depth increases and as the trace speed decreases, the channel depth increases as well. This therefore means that the $100 \mathrm{~W}$ channels traced at $50 \mathrm{~mm} / \mathrm{s}$ should be the deepest channels. It was seen in the depth maps that the shape of the groove no longer followed the Gaussian profile as all the other lines did in addition to being much wider. This can possibly be attributed the increased energy, a higher energy input concentration and longer exposure time, thus creating a larger heat effected zone which may possibly be recasting the burnt, ejected mass. Another possibility is when the material is burnt, boiled or vaporized, due to the high energy levels involved, there is a possibility the ejected mass is obstructing the beam and absorbing a significant portion of the energy from the laser. During the experimentation and the cutting of the channels, large amounts of burnt material were observed being ejected from the material and being blown around the containment

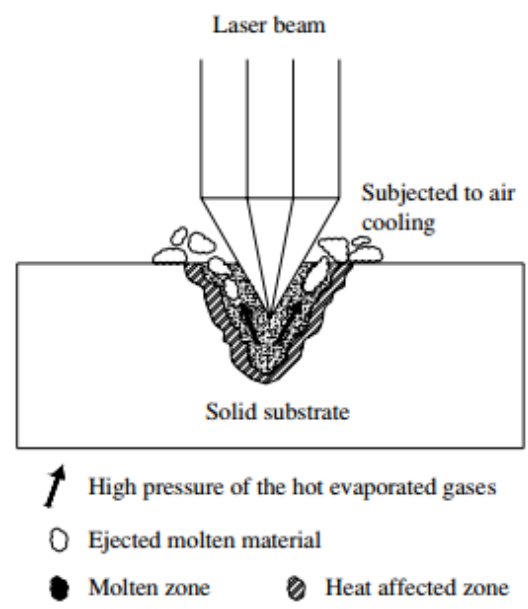

Figure 7. The schematic model of the formation of bulges and the material ejection process during polymer machining by laser [10] vessel of the laser. Figure 7 shows schematically the process which material goes through as it is being exposed to a laser beam. The material is ejected by the rapid expansion of high temperature vaporized and molten material. This can cause the material to be recast along the edges, which is visible Figure 4(d). This would also explain why the repeatability and quality of the channel is drastically reduced. These hypotheses will need to be investigated further incorporating SEM imagery and high-speed imaging of the process itself. Investigation of the material structure within the groove can then be carried out in addition to observing the behavior of ejected mass. The observed behavior however, does indicate a loss of control of the process at higher energy levels. A loss of control is evident when the dramatic increase in maximum variance with respect to the channel depth, as seen in Figure 8, is investigated in addition to energy level. The ribbon plots in Figures 5 and 6 demonstrate that as laser power increases the variation in depth increases as repeatability decreases, regardless of trace speed or overall cut depth.

Besides this observation, the data had $\mathrm{R}^{2}$ values of between 0.926 and 0.997 indicating an extremely strong correlation between trace speed and channel depth.

\section{B. Channel Profile: Evaluation of Channel Quality}

The channel quality can be quantified using the variance graph produced for each sample as seen in Figure 3. These values were then plotted in Figure 8. It can be seen that above $125 \mathrm{~mm} / \mathrm{s}$ there is no major relationship between speed, power and channel quality. However, as the amount of energy input into the material increases and the exposure time is extended, the channel quality is further reduced evidenced by Figure 8 . It shows a strong negative correlation between both trace speed and variance. Some of this increase can be attributed to the increased channel depth, however, the same trend still exists when running this comparison with the variance as a percentage of the channel depth.

\section{Channel Profile: Slope Angle}

Due to the configuration of the laser, the slope angles

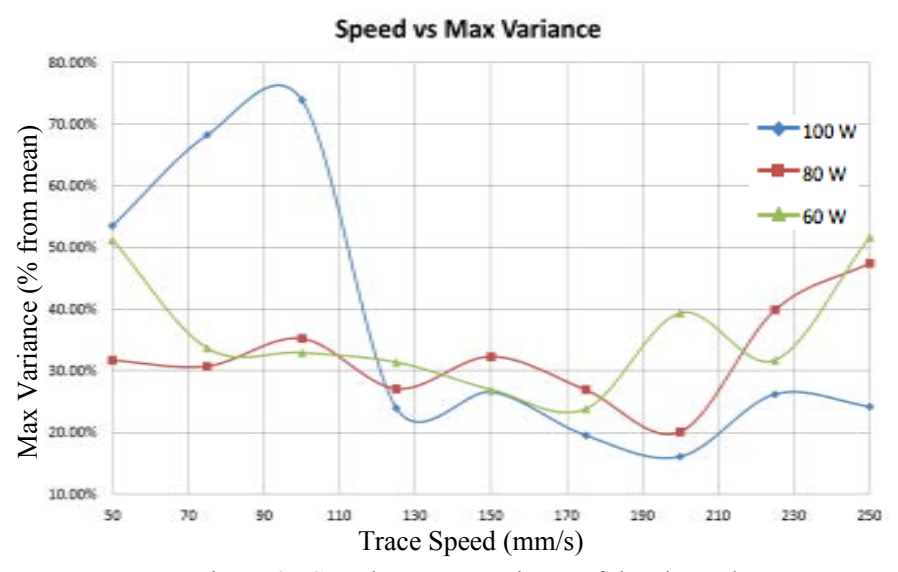

Figure 8. Speed vs Max Variance of the channel 
produced are largely dependent on the incidence of the beam. The laser used a scanning head configuration, which uses an articulated mirror to redirect the beam. This means that the incidence angle between the beam and material surface changes as the beam follows its programmed cutting paths[8]. This angle is, at its maximum will be approximately $10^{\circ}$ away from vertical. This angle is not enough to cause any noticeable effect to the depth as seen in the relatively consistent depths achieved across multiple samples. It will however affect the slope angle of the grooves. The advantage of using a scanning head such as this is the ability to achieve much higher trace speeds than a conventional Cartesian bed laser. In addition to higher trace speeds, scanning heads are less affected by speed ramping due to the much lower mass and thus the inertial effects generated during acceleration and deceleration of the laser when compared to an equivalent Cartesian bed system.

\section{Channel Profile: Edge Transition Type}

Two types of edge transition exist within the scope of this experiment, smooth and blunt. A blunt transition is defined as having a sharp drop-off from the surface to the bottom of the channel is narrower than the depth. A smooth transition is one that is wider than the depth. It was found that there was no correlation between transition type and either power or speed. The link between the power and transition produced a spearman coefficient of 0.068 , and for the speed and transition link a value of -0.582 . This shows there is a modest correlation between speed and the likelihood of a specific transition occurring, however it is far from a strong link. The transition depth is more likely affected by the angle of incidence, for which the laser interacts with the material; this was not a controlled variable for this experiment. This is due to the way a scanning head

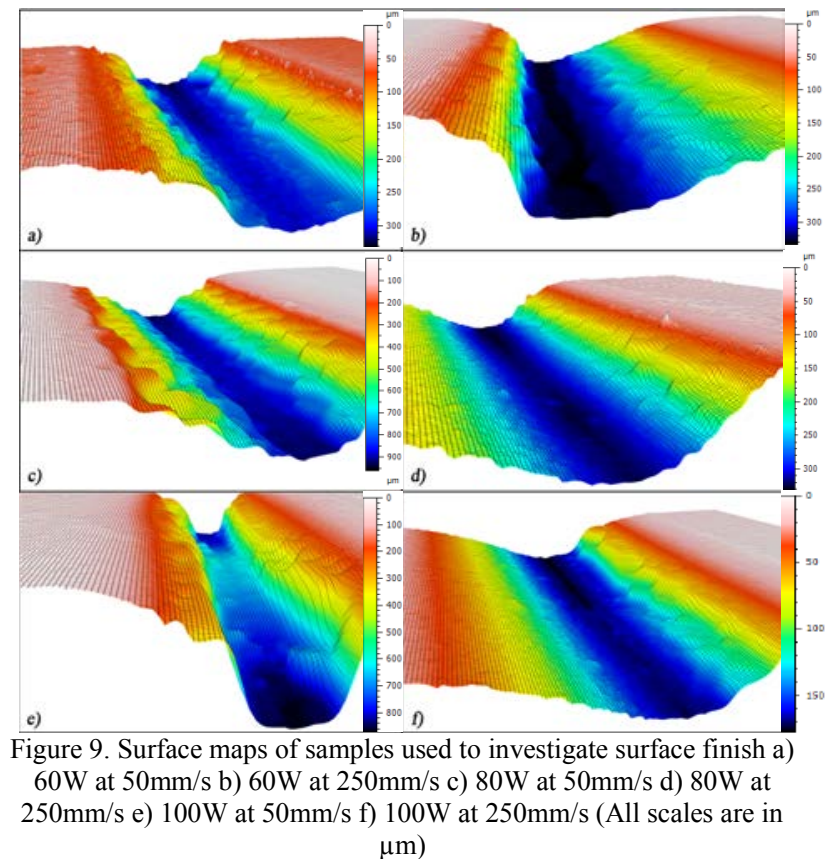

operates.

\section{E. Material Integrity}

It can be seen in Figure 4(b) that cracking has occurred at the bottom of the channel likely due to the high thermal stresses induced within the material. These stresses are caused by the extremely rapid temperature rise and steep thermal gradient between the areas of material exposed to the laser and the immediate surrounding areas, both on the surface and below the penetration depth of the beam. As of yet it is unknown if this structure of cracks which are less than $200 \mathrm{~nm}$ in width will have an effect on the surface wettability with Galinstan or more importantly absorb the fluid and allow penetration of the fluid into the material.

a)

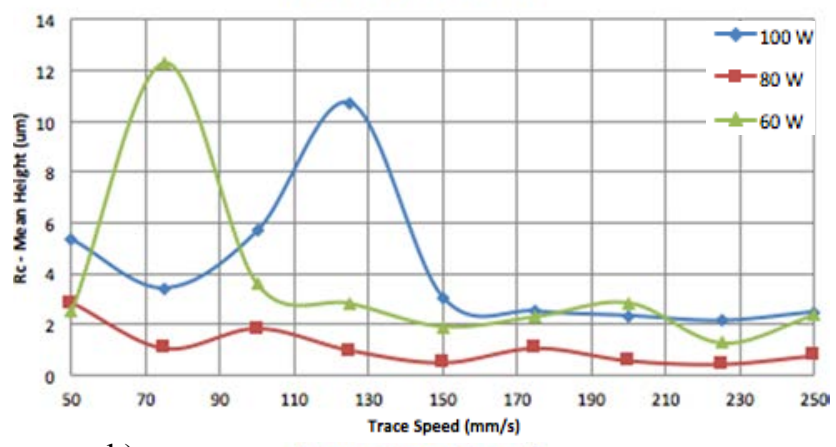

b)

\section{Ra vs Trace Speed}

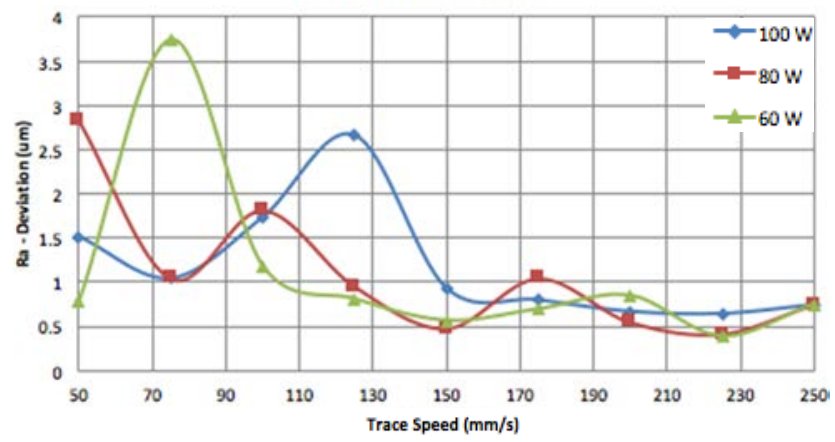

c)

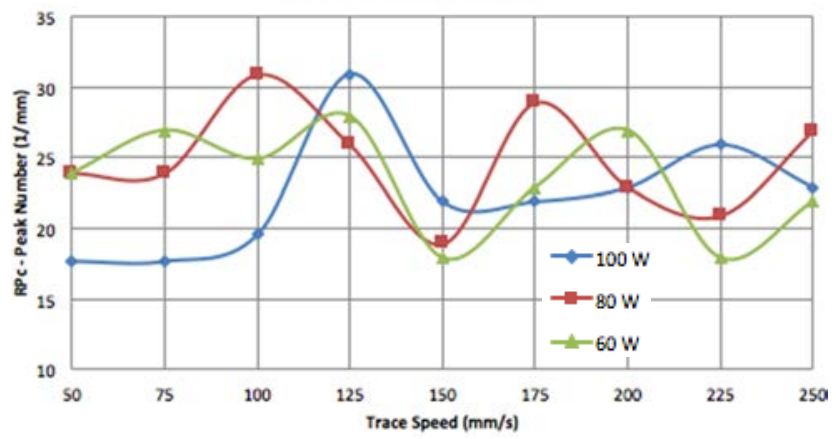

Figure 10. Data extracted from each samples surface profile report presented above. a) Mean peak height vs trace speed. b) Arithmetical mean deviation of the mean height vs trace speed. c) Average number of peaks per mm vs trace speed 


\section{F. Surface Finish}

Surface texture is a significant part of overall surface finish and can be quantified using various metrics that are defined by various standards, specifically BS EN ISO 4287 [9]. From this standard, a specific set of metrics can quantifiably allow the comparison of a set of surfaces. These indicators are Mean Peak Height (Rc), Arithmetical Mean Deviation (Ra) and the number of peaks per millimeter (RPc). The use of these metrics defines the height and frequency of peaks and troughs on the surface as well as defining their deviation from the maximum value. A typical report generated by Mountains Map from each depth map as seen in Figure 9, can be created and plots of these values from the samples can be seen in Figure 10. The only drawback to using these values is that they can only be generated for a single profile extracted from the three dimensional depth maps. Each profile was selected from the deepest part of the channel.

It can be seen from Figure 10(a) that Mean Peak height appears to be affected by the amount of power input into the material but not by the trace speed. However, the $80 \mathrm{~W}$ power output appeared to generate the smoothest channels with the overall lowest mean peak heights, however when this value is paired with the mean deviation shown in Figure 10(b), this relationship becomes far less significant as there is discernable relationship between power and the deviation of peak height. There is however, a correlation between the deviation and trace speed $\left(\mathrm{R}^{2}=-0.581\right)$, with higher trace speeds producing a more even and nominal channel surface. This is likely due to shorter exposure times to the laser and thus reducing the thermal stresses on the material and resulting in less thermal fracture and additional burning, where the material does not have the required energy to be ejected from the exposed zone. As for the number of peaks that appear over the measured length, there is no correlation to trace speed or power, which is apparent when the $\mathrm{R}^{2}$ values of -0.011 and -0.116 are examined. This can clearly be seen in the chaotic nature of Figure 10(c). This is very likely due to the chaotic and violent nature of the burning and vaporization process that occurs within the laser's focal point on the surface.

\section{CONCLUSION}

From the results obtained, it can be seen there is a strong correlation among laser power, trace speed and channel depth. However, increases in power can negatively affect the channel quality and geometry creating channels that are less repeatable and have increased variability across their length; this makes higher laser powers unsuitable for the manufacture of Galinstan carrying channels as it will create current bottlenecks in addition to increasing the channel resistance. In addition to higher power levels negatively affecting channel quality, lower trace speeds also had this effect. As a result, this places a limitation on channel dimensions as in order to create deeper channels, repeatability and channel quality would need to be sacrificed. Further testing of the channel surface with respect to its interaction with the fluid Galinstan is currently being carried out to investigate how the material flows through and wets to the channel wall surface. Simulation and experimental work is also being carried out to investigate how the channels deform when undergoing mechanical stress, which is a vital piece of knowledge to know how the conductors would perform when in use.

\section{ACKNOWLEDGMENTS}

The authors acknowledge the use of facilities within the Loughborough Materials Characterisation Centre and the Sports Technology Institute. The authors would also like to thank Jagpal Singh for his assistance within the Wolfson School of Mechanical, Manufacturing and Electrical Engineering Metrology Lab for his assistance and patience with regard to data acquisition.

\section{REFERENCES}

[1] Wearable Electronics Sensors: For Safe and Healthy Living. Springer, 2015.

[2] R. Bringans, "Challenges and opportunities for the flexible electronics industry." Palo Alto.

[3] J. a Fan, W.-H. Yeo, Y. Su, Y. Hattori, W. Lee, S.-Y. Jung, Y. Zhang, Z. Liu, H. Cheng, L. Falgout, M. Bajema, T. Coleman, D. Gregoire, R. J. Larsen, Y. Huang, and J. a Rogers, "Fractal design concepts for stretchable electronics," Nat. Commun., vol. 5, p. 3266, Feb. 2014.

[4] T. Liu, P. Sen, and C. J. Kim, "Characterization of nontoxic liquid-metal alloy galinstan for applications in microdevices," J. Microelectromechanical Syst., vol. 21, no. 2, pp. 443-450, 2012.

[5] M. K. Armstrong, "PCB design techniques for lowest-cost EMC compliance. Part 1," Electron. Commun. Eng. J., vol. 11, no. 4, pp. 185-194, Aug. 1999.

[6] K. Ren, J. Zhou, and H. Wu, "Materials for Microfluidic Chip Fabrication."

[7] S. M. Westwood, S. Jaffer, and B. L. Gray, "Enclosed SU-8 and PDMS microchannels with integrated interconnects for chip-to-chip and world-to-chip connections," J. Micromechanics Microengineering, vol. 18, no. 6, p. 064014, Jun. 2008.

[8] N. S. Shanmugam, G. Buvanashekaran, K. Sankaranarayanasamy, and K. Manonmani, "Influence of Beam Incidence Angle in Laser Welding of Austenitic Stainless Steel using Finite Element Analysis," Multidiscip. Model. Mater. Struct., Jul. 2013.

[9] The British Standards Institution, "BS EN ISO 4287 Geometrical product specification (GPS). Surface texture: Profile method. Terms, definitions and surface texture parameters." The British Standards Institution, 2000.

[10] C. K. Chung, Y. C. Lin, and G. R. Huang, "Bulge formation and improvement of the polymer in $\mathrm{CO} 2$ laser micromachining," J. Micromechanics Microengineering, vol. 15, no. 10, pp. 1878-1884, Oct. 2005. 